\title{
História Global do Trabalho: um olhar desde o Brasil
}

\section{Henrique Espada Lima**}

Resumo: Este artigo pretende refletir sobre os temas de investigação e os lugares de produção (acadêmicos, institucionais e outros) da chamada "história global do trabalho". O objetivo do texto é levantar algumas questões sobre como o interesse renovado pelas comparações, conexões e processos de agregação no campo da história pode inspirar o debate histórico brasileiro sobre a história social do trabalho, de modo a pensar seu lugar dentro dessas novas inflexões da pesquisa.

Palavras-chave: história do trabalho; história global; historiografia.

Abstract: The article focus on the so called "global labor history", discussing its topics of research, and spaces of production (institutional, academic and other). The article's goal is to address how the current, and renewed, interest on comparisons, connections, and processes of entanglement/aggregation in history could inspire the Brazilian historical debate on the social history of labor, and to discuss in which ways the Brazilian scholarship could find a place in these new research trends.

Keywords: Labor History; Global History; Historiography.

* Este artigo é uma versão um pouco ampliada da minha intervenção na mesa-redonda intitulada “História Global do Trabalho: redes e pesquisas" no V Seminário Internacional Mundos do Trabalho, que teve lugar em Porto Alegre em setembro de 2018. Como o(a) leitor(a) não terá dificuldade de ver, o artigo tem ainda o formato de uma intervenção pública, mais breve e argumentativo, e menos formal e demonstrativo. Agradeço aos demais membros da mesa, Antonio Negro, Diorge Konrad e Raquel Varela, bem como a Aldrin Castellucci pelo convite para submeter este texto à Mundos do Trabalho.

** Doutor em História pela Universidade Estadual de Campinas (Unicamp). Professor do Departamento de História da Universidade Federal de Santa Catarina (UFSC). Bolsista de Produtividade em Pesquisa 1D do CNPq. Contato: henrique.espada@ufsc.br 
$\mathrm{O}$ objetivo deste texto é refletir sobre o interesse corrente pela chamada "história global do trabalho", tentando pensar sobre como esse interesse reflete, ou pode refletir, no debate historiográfico brasileiro e em seus caminhos de pesquisa.

Por "história global do trabalho" entendo o esforço coletivo de pesquisadores ligados à história social do trabalho que, desde a primeira década deste século, vêm tentando reconstruir ou repensar o aparato crítico, os contextos, as categorias de análise, os objetos de estudos e os espaços onde se investiga e se dá sentido às narrativas sobre a história do trabalho e dos trabalhadores. Os lugares de produção desses estudos históricos concentram-se, ao menos até agora, sobretudo nos países norte-atlânticos e têm como protagonistas pesquisadores de várias origens, mas que são de algum modo conectados a instituições de pesquisa nos Estados Unidos e na Europa.'

A despeito da sua origem indiscutivelmente norte-atlântica, esse campo emergente também é marcado pelo esforço ativo de "descentrar" a narrativa histórica, desafiando noções estabelecidas de centro e periferia, de modo a integrar à "história global" trajetórias e processos históricos, bem como experiências de trabalho e de trabalhadores localizados em diferentes partes do globo, e sobretudo no chamado "Sul Global" - uma referência geopolítica que supõe certa coerência e paralelismo nas experiências dos países periféricos do sistema capitalista global, bem como as antigas periferias coloniais. Na América Latina, e no Brasil em particular, esse interesse articula-se com iniciativas locais cujo objetivo é conectar as histórias produzidas no país aos debates e questões que brotam desse contexto internacional. Exemplos dessa articulação encontram-se em vários campos, como nos estudos sobre a circulação de ideias políticas e indivíduos em contextos transnacionais, das relações entre instituições sindicais e políticas de diferentes países, ou no estudo da atuação de agências multilaterais (como a Organização Internacional do Trabalho) e seu impacto internacional, estudos sobre imigrações de trabalhadores, e, naturalmente, histórias das relações entre as dinâmicas socioeconômicas das sociedades escravistas e a expansão do capitalismo. ${ }^{2}$ É uma lista de temas importantes, mas está longe de ser completa.

1 O texto que é em geral tomado como referência inaugural desse debate no campo da história social do trabalho é de autoria conjunta de Marcel van der Linden e Jan Lucassen: Prolegomena for a Global Labour History. Amsterdam: International Institute of Social History, 1999 (disponível em http://www.iisg.nl/ publications/prolegom.pdf). O Instituto de História Social de Amsterdã é certamente um dos espaços de produção e fomento desse projeto, como veremos. Um outro exemplo de iniciativas que tentam atrair o debate para os espaços de produção de conhecimento na Europa é a iniciativa financiada pelo Ministério de Educação e Pesquisa da Alemanha, intitulada "IGK Work and Human Life Cycle in Global History". Esse centro, sediado na Universidade Humboldt em Berlin, estabelecido em 2009 e dirigido pelo africanista alemão Andreas Eckert, reúne um colégio de fellows renovado a cada ano e que foi co-responsável pela construção de uma rede de mais de 150 pesquisadores associados oriundos de vários países europeus, americanos, africanos e asiáticos reunidos em torno do tema da história global do trabalho (ver sua página na internet: https://rework.hu-berlin.de/en/news.html). Para uma perspectiva menos orientada pelas redes acadêmicas europeias - escrito por alguém excepcionalmente bem posicionada para subsidiar essa discussão, e com fortes ligações com os estudos sobre o trabalho no Brasil - ver o artigo de Barbara Weinstein: "Globalizando a História do Trabalho: o caso da revista International Labor and Working-Class History", Mundos do Trabalho, v. 9, n. 18, p. 11-23, jul.-dez. 2017.

2 Seria ambicioso demais fazer uma lista minimamente abrangente de trabalhos que seguem as linhas que mencionei, que vêm se multiplicando como números temáticos de revistas, teses e livros que começam a aparecer. Algumas iniciativas e trabalhos recentes merecem, entretanto, serem mencionados: certamente o GT ANPUH Mundos do Trabalho é um dos grupos que vem tentando ativamente pensar a história global do trabalho, sobretudo nos seus eventos internacionais acontecendo bianualmente desde 2010. Entre suas iniciativas recentes, vale destacar o número de International Review of Social History intitulado "Brazilian Labour History: New Perspectives in Global Context" e organizado por Alexandre Fortes, Paulo Fontes e David Mayer (volume 62, edição especial S25, dezembro 2017). Outras iniciativas 
Vale acrescentar que a história global do trabalho participa de, mas não se confunde completamente com, uma inflexão importante que se opera em parte do campo historiográfico contemporâneo, marcado pelo interesse crescente nas comparações, nas conexões e entrelaçamentos entre processos locais e nacionais, e dinâmicas translocais e transnacionais, com reflexos na história social, econômica e cultural. Mas como a história global do trabalho compartilha muitos dos elementos dessa inflexão, também compartilha as críticas que possa merecer.

Com essa definição provisória e incompleta do campo, pretendo apenas estabelecer de saída os parâmetros que guiam a intervenção que segue, que não pretende ser exaustiva nem conclusiva no que concerne às questões que levanta.

Sobre o tema da história global do trabalho, tive a oportunidade de me debruçar brevemente em algumas ocasiões, ${ }^{3}$ e as observações pessoais que eu fiz então, bem como as formulações que virão a seguir, são fruto das observações coletadas na participação em encontros acadêmicos, na interlocução com pesquisadores e na leitura de seus trabalhos durante a última década. Minha aproximação a essas questões deriva, em primeiro lugar, da minha posição como um observador curioso das transformações do campo historiográfico: eu dediquei uma parte da minha trajetória acadêmica a tentar entender o significado da emergência da micro-história dentro desse campo, tentando refletir sobre as suas origens, seu desenvolvimento, a natureza e os limites da sua contribuição intelectual para os modos pelos quais pensamos a história. ${ }^{4}$ Eu não tenho a ambição de fazer o mesmo tipo de estudo profundo sobre a chamada história global, mas certamente acho que vale a pena fazer perguntas semelhantes, sobretudo sobre a natureza e os limites da contribuição intelectual que a história global tem o potencial de fazer.

Em segundo lugar, o outro posto de observação que ocupo, e desde o qual eu gostaria de falar sobre a história global do trabalho, é o de testemunha interessada de alguns dos debates, e um participante episódico das redes de pesquisadores que de modo mais ou menos militante trouxeram o tema da história global do trabalho à voga. ${ }^{5}$ Dentro dessas redes, com participantes oriundos de diversas partes do globo, as posições sobre a história global divergem substancialmente. Como historiador social que tenta pensar as relações entre o micro e o macro, minha própria posição, de saída, tenta articular, por um lado, um certo ceticismo saudável com as "modas" historiográficas, e, por outro, uma curiosidade sincera

dignas de nota, sobretudo sobre a história da escravidão, têm lugar no Laboratório de Estudos sobre o Brasil e o Sistema Mundial (Lab-Mundi) coordenado por Rafael de Bivar Marquese, João Paulo Pimenta e José E. Vieira de Melo na Universidade de São Paulo. Entre algumas de suas iniciativas, vale destacar, por exemplo, a obra coletiva organizada por R. Marquese e Ricardo Salles, Escravidão e capitalismo histórico no século XIX: Cuba, Brasil e Estados Unidos. Rio de Janeiro: Civilização Brasileira, 2016.

3 Por exemplo: LIMA, Henrique Espada. "No baú de Augusto Mina: o micro e o global na história do trabalho". Topoi, Rio de Janeiro, v. 16, n. 31, p. 571-595, 2015. Ver também minha contribuição à mesa-redonda intitulada "Pensar o global como categoria historiográfica", no IX Encontro Nacional de História da Educação, acontecido em João Pessoa, em agosto de 2017: LIMA, Henrique, “Desprovincializar o local: notas sobre o global como categoria historiográfica" (inédito).

4 LIMA, Henrique Espada. A micro-história italiana: escalas, indícios e singularidades. Rio de Janeiro: Civilização Brasileira, 2006.

5 Vale citar minha participação ativa, desde 2008, na conferência bianual da International Labour History Conference, organizada pela Association of Indian Labor Historians (Delhi, Índia), com o comparecimento de historiadores de vários países e apoio direto do International Institute of Social History de Amsterdã. Entre 2011 e 2012, fui pesquisador visitante no Internationalen Geisteswissenschaftlichen Kollegs "Work and Human Life Cycle in Global History" - uma rede interdisciplinar de pesquisadores sobre o trabalho interessados na história global, sediada na Humboldt Universität-zu-Berlin (Alemanha). Participei ainda de outros eventos sobre o tema da global history em Istambul (Turquia), Linz (Áustria), Johannesburg (África do Sul), além de Florianópolis e Rio de Janeiro. 
por aquilo que se produz nesse campo emergente. Sobretudo me interessa na história global mais as "perguntas" que ela pode nos ajudar a formular do que necessariamente as respostas que até agora se apresentaram.

É nesse espírito que gostaria de levantar pontos para uma discussão, oferecendo alguns comentários sobre o que eu julgo serem os riscos em que pode incorrer na adoção acrítica da história global como o "novo" caminho a seguir. Ao final do texto, eu gostaria de falar brevemente sobre como eu vejo aquilo que essa nova inflexão historiográfica pode contribuir para o enriquecimento da nossa própria maneira de ver e escrever a história. Vou tentar fazer isso sondando um pouco minha própria experiência com esse debate.

Vou começar falando um pouco sobre o que eu chamei os "riscos" da nova inflexão em direção a uma "história global". Aqui, eu não vou mencionar as várias vertentes e variações que compõem o seu quadro, mas vou tentar levantar questões que me parecem se colocar transversalmente a muitas dessas versões. Vou me concentrar em dois conjuntos de riscos, lembrando mais uma vez que não se trata de uma lista completa. O primeiro conjunto é de ordem teórica e historiográfica; o segundo, combinando uma dimensão institucional a uma questão que toca, na falta de palavra melhor, a sociologia do conhecimento, na medida em que se refere à criação ou manutenção de hierarquias e assimetrias na circulação e controle do conhecimento em uma escala ampla. Outras subdivisões poderão ser acrescentadas: como eu disse antes, não se trata de esgotar o assunto, mas levantar pontos para uma discussão.

Vamos ao primeiro ponto: entre os muitos motivos para a emergência do "global" como categoria síntese a descrever a atual onda historiográfica, vários comentadores concordam em ver na emergência do fenômeno e o conceito da "globalização" como seu motivador principal. ${ }^{6} \mathrm{~A}$ despeito da insistência de alguns dos seus praticantes em dizer que a ideia da "história global" não se confunde com a história da globalização - Marcel van der Linden talvez seja o melhor exemplo7 - não acho que exista alguém que possa discordar que os dois conceitos se relacionam, em maior ou menor grau. E de fato, não acredito estar exagerando ao dizer que os principais livros que são tomados como exemplos paradigmáticos da "história global" são livros que tratam diretamente das origens da globalização e da modernidade capitalista. Cito dois: o já clássico de Kenneth Pommerantz, "A Grande Divergência. A China, a Europa, e a formação da economia mundial moderna", publicado em 2000; e o recente livro de Sven Beckert, "O Império do Algodão. Uma história global”, 9 publicado em 2015. Cito esses exemplos, demarcando a diferença com as "histórias conectadas", ou a "história atlântica", ou as histórias "transnacionais" que se relacionam, mas não necessariamente se confundem, com a história global.

6 Como afirma Sebastian Conrad na primeira página de seu livro - considerado a melhor introdução sobre o tema - What is Global History?. (Princeton: Princeton University Press, 2016, p. 1). Para uma perspectiva mais crítica sobre essa relação, ver: ECKERT, Andreas, "Why all the fuss about Global Labour History?". In: ECKERT, Andreas (ed.) Global Histories of Work. Berlin: De Gruyter, 2016, p. 3-22; COOPER, Frederick. "What is the Concept of Globalization Good for? An african historian's perspective". African Affairs, v. 100, n. 339, p. 189-213, abr. 2001. Ver também as observações de Barbara Weinstein sobre essas discussões no contexto da história do trabalho nos EUA, "Globalizando a história do trabalho".

7 Ver, por exemplo: VAN DER LINDEN, Marcel. "The Promise and Challenges of Global Labor History". International Labor and Working Class History, v. 82, p. 57-76, outono de 2012.

8 POMERANZ, Kenneth. A Grande Divergência. A China, a Europa e a formação da economia mundial moderna. Lisboa: Edições 70, 2013 (a edição original em inglês é de 2000).

9 BECKERT, Sven. Empire of Cotton: A Global History. Nova York: Vintage Books, 2014. 
A história global, nesses dois exemplos (mas poderíamos citar outros), torna-se um modo de entender as origens da modernidade capitalista e da globalização, procurando restabelecer os laços e as mediações que ligam as formas anteriores de articulação dos mercados em escala global às formas contemporâneas. Não estou sugerindo que não sejam visões críticas do capitalismo e da globalização nem estou afirmando que sejam apenas novas versões da narrativa triunfante do "desenvolvimento" que tem como protagonista a Europa e os países norte-atlânticos. Ao contrário, essas são visões que estão fortemente fincadas em uma tentativa de criticar as narrativas tradicionais e celebratórias da modernidade capitalista, tentando mostrar o papel central do colonialismo e da escravidão para dar nexo a essas histórias. Mas não há dúvida que esses são trabalhos que pensam a história global como uma forma de genealogia do presente. O télos da narrativa - o ponto de chegada que dá sentido ao processo - se encontra de um modo ou de outro nessa conexão entre o passado e a modernidade de hoje.

Rafael Marquese fez uma brilhante palestra recentemente em Florianópolis sobre o tema da história global, ${ }^{10}$ onde ele defendia exatamente essa ideia, de que a história não pode abrir mão da "teleologia", que ele entendia como uma forma de genealogia do presente: em outras palavras, a pergunta sobre os processos históricos, globais, de longa, média e curta duração que produziram a situação que vivemos. O ponto de vista assumido por Marquese é informado pela sua própria pesquisa, bem como pelo seu empenho direto em conectar o debate brasileiro - e a tradição de estudos à qual explicitamente se vincula"1 - às discussões emergentes sobre as relações globais entre escravismo e capitalismo. O seu trabalho de pesquisa - que não temos nenhum motivo para não incluir no horizonte geral de uma história do trabalho - compartilha muitos atributos da discussão recente sobre a história global. ${ }^{12}$ Em suas investigações, ele explora as conexões entre a economia cafeeira do Sudeste brasileiro durante o império no século XIX com a economia da chamada "segunda escravidão" nos Estados Unidos e Cuba, retomando e atualizando uma tradição de estudos que nasce da geração de historiadores a que pertenceu Caio Prado Júnior, Eric Williams e C.L.R. James e que se estende até os estudos sobre a teoria da dependência e os sistemas mundo; e que investiga, nas suas palavras, "a formação do estado nacional brasileiro nos quadros da economia-mundo capitalista do século XIX". ${ }^{3}$ Uma pergunta "global" (ou uma pergunta "total" na acepção braudeliana mais cara à Marquese), que obviamente não exclui a pesquisa em pequena escala, ${ }^{14}$ mas que é profundamente marcada pelo impulso em estabelecer modelos explicativos fortes.

10 MARQUESE, Rafael de Bivar. "História Global: métodos, problemas e perspectivas". Palestra realizada no dia 29 de agosto de 2018 no auditório do EFI, Universidade Federal de Santa Catarina (inédita).

11 Aqui me parece importante reconhecer o quanto Marquese reivindica diretamente sua dívida para com a longa tradição de investigação que, desde Caio Prado Júnior, passando por Celso Furtado e os estudos cepalinos, até as formulações de Fernando Novais, a "teoria da dependência" e outros autores mais recentes, se esforçou em pensar os entrelaçamentos entre a dinâmica econômica brasileira e as assimetrias e dependências ligadas à dinâmica do colonialismo e à expansão dos mercados mundiais na longa duração. Sobre isso, ver o seu artigo/resenha: "Capitalismo \& Escravidão e a historiografia sobre a escravidão nas Américas”, Estudos Avançados, São Paulo, v. 26, n. 75, p. 341-354, 2012.

12 Sobre isso, ver o sítio do LabMundi na internet: http://labmundi.fflch.usp.br.

13 MARQUESE, Rafael de Bivar. "Estados Unidos, Segunda Escravidão e Economia Cafeeira do Império do Brasil". Almanack, Guarulhos, n. 5, $1^{\circ}$ semestre de 2013, p. 51. As referências à "segunda escravidão" derivam do trabalho pioneiro de Dale Tomich sobre o assunto. Ver o seu: Pelo Prisma da Escravidão: Trabalho, Capital e Economia Mundial. São Paulo: Edusp, 2011.

14 Como sugere o artigo de um dos colaboradores (e inspiradores do trabalho) de Marquese: TOMICH, Dale. “A Ordem do Tempo Histórico: a Longue Durée e a Micro-história”. Almanack, Guarulhos, n. 2, 2ºmestre de 2012, p. 28-51. 
Aqui, trata-se certamente de uma pergunta que procura encontrar conexões e mediações entre as conjunturas políticas e econômicas centrais na formação do Brasil contemporâneo e os processos de larga escala e longa duração que estabeleceram os pilares do mundo moderno. São indagações, portanto, sobre os "porquês", sobre a gênese do mundo contemporâneo, marcada quase inevitavelmente por um sentido forte de hierarquia de mediações e uma insistência, mesmo que ponderada, no caráter ultimamente determinado da realidade social.

Já que a chave que se quer assumir aqui é a do distanciamento crítico, uma pergunta pode ser feita de saída: Marquese está errado em formular suas questões desse modo, e desenhar sua própria versão da história global nos termos que propõe? É claro que não. Não há como simplesmente ignorar a força e a urgência da pergunta teleológica sobre as origens históricas do nosso presente. Mas não se pode dizer que é uma pergunta nova, ainda que de muitos modos atualize e dê novo espírito à indagação anterior. E desconfio que a resposta (ou respostas) propostas pela história global também não sejam. Alguém pode argumentar que a falta de originalidade não é sozinha suficiente para invalidar o projeto. É verdade. Mas acho que o risco não reside aí, sobretudo para nós que, desde um ponto de vista da história social do trabalho, aprendemos que há outras perguntas além dessa.

Na tradição da história social na qual muitos de nós se construíram, tem importância crucial uma outra pergunta, não menos importante: aquilo que, na história, não "venceu”, mas que permaneceu como o caminho não percorrido, aquilo que não chegou "até aqui". Não preciso lembrar aqui o quanto significou para a história social o impulso intelectual e político de salvar essas outras histórias da "enorme condescendência da posteridade". Uma resposta para a inevitabilidade da teleologia, ou pelo menos um antídoto a ela, está contida nessa imagem de E. P. Thompson, para quem:

\footnotetext{
"Não deveríamos ter como único critério de julgamento o fato de as ações de um homem se justificarem, ou não, à luz da evolução posterior. Afinal de contas, nós mesmos não estamos no final da evolução social. Podemos descobrir, em algumas das causas perdidas do povo da Revolução Industrial, percepção de males sociais que ainda estão por curar". ${ }^{15}$
}

Ou ainda, e me desculpem se eu também invoco outra fonte de inspiração, o bom e velho Walter Benjamin, para quem: "O cronista que narra os acontecimentos, sem distinguir entre os grandes e os pequenos, leva em conta a verdade de que nada que um dia aconteceu pode ser considerado perdido para a história". ${ }^{16}$

Em outras palavras, um papel central da história social - que é o de nos dar instrumentos conceituais e mesmo políticos para tomar distância crítica do nosso próprio presente e as suas possibilidades - pode ficar grandemente prejudicado por uma atitude intelectual que se contenta com o horizonte estabelecido pela pergunta teleológica. Difícil não ver na celebração da história global ecos dessa atitude.

Enfim, poderíamos elencar ao menos duas outras razões para desconfiar da pretensa superioridade científica de uma perspectiva que prioriza uma abordagem

15 THOMPSON, E. P. A Formação da Classe Operária Inglesa. Volume 1. Rio de Janeiro: Paz e Terra, 1987, p. 13.

16 BENJAMIN, Walter. "Sobre o conceito da história". In: Obras Escolhidas, volume I. São Paulo: Brasiliense, 1987, p. 223 (tese 3). 
sistêmica e estrutural, conferindo ao estudo dos casos particulares uma função exemplar e acessória, e relegando o interesse pelas anomalias e exceções ao campo do anedótico e inessencial. Primeiro, porque se arrisca a perder a oportunidade de corrigir as distorções produzidas por uma visão que prioriza os resultados visíveis e as dinâmicas autoconscientes da realidade histórica, que frequentemente ignoram ou silenciam, mesmo do ponto de vista documental, processos mais sutis ou menos conscientes que, a despeito disso, tiveram impacto real e verificável - ainda que frequentemente silencioso - sobre as formas e conteúdos tomados pelos processos sistêmicos e estruturais que se quer compreender. Em segundo lugar, mas não menos importante, é que o estudo das anomalias e das exceções tem o potencial cognitivo de revelar as contradições internas, as incoerências e, portanto, as fragilidades desses mesmos sistemas, podendo, portanto, ensinar algo sobre a sua própria contingência histórica. ${ }^{17}$

Tudo isso converge, acredito, para reconhecer que é uma tarefa essencial da história não abandonar a ambição de levar os atores sociais a sério, ${ }^{18}$ pois talvez essa seja a única atitude que pode criar os antídotos a uma tendência que parece ser inerente à história global, que é a de produzir, na mesma operação, uma história da globalização e uma justificativa da inevitabilidade desse processo. Em outras palavras, uma paradoxal celebração do capitalismo e da globalização, mesmo quando coloca esses processos como objeto de crítica. Eu acho que um argumento semelhante pode ser feito à perspectiva da economia-mundo de extração walleirsteiniana, a quem, claramente, essa "história global" certamente deve muita coisa. ${ }^{19}$

Relacionadoaisso, meparecereveladorque um dosresultadosimediatamente reconhecíveis em algumas dessas histórias "globais" e a nova narrativa da história do capitalismo, por exemplo, é que ela também parece dispensar algumas das abordagens que julgávamos que tivessem sido incorporadas de uma vez por todas em nosso questionário de pesquisa e campo de investigação. Um exemplo disso é a dinâmica do gênero e da sexualidade, que trouxe contribuições formidáveis, mas que nesses estudos parece retornar à periferia dessa "grande" história, ameaçada de ser vítima da "enorme condescendência" do presente "globalizado". ${ }^{20}$

Pensando no risco de perder a dimensão da irredutibilidade da experiência humana - e, portanto, do olhar atento sobre aquilo que escapa à modelização e à macronarrativa - me parece importante formular a pergunta sobre se é possível conciliar essas duas questões de fundo que animam a história social. Não há dúvida que há potencial em fazer pensar o micro e o global, a singularidade e a universalidade, como complementares, mesmo que os contornos dessa

17 Um exemplo de pesquisa que ilustra meu argumento continua sendo: LEVI, Giovanni. A herança imaterial. Trajetória de um exorcista no Piemonte do século XVII. Rio de Janeiro: Civilização Brasileira, 2000.

18 LEPETIT, Bernard. “L'histoire prende-elle les acteurs au sérieux?”. EspaceTemps, n. 59-61, p. 112-122, 1995.

19 Difícil não ver esse tipo de celebração ambígua em uma obra tão importante para essa tradição de estudos, como são os volumes publicados por Fernand Braudel sob o título Civilização Material e Capitalismo. Séculos XV-XVIII: I. As estruturas do cotidiano; II. Os jogos da troca; III. O tempo do mundo. São Paulo: Martins Fontes, 1995 (3 volumes). O projeto de Immanuel Wallerstein, também em três volumes publicados entre 1979 e 1989 - The Modern World System (pela Academic Press), não foge à regra. Também nesse sentido, é reveladora a observação de Beckert sobre o "capitalism's awe-inspiring increases in human productivity and consumption" (Beckert, Empire of Cotton, p. xiii). "Awe" pode ser traduzido como temor reverencial, sugerindo as dimensões quase míticas que o processo de estabelecimento do capitalismo costuma ser tratado nesses estudos.

20 Sobre a ausência das discussões de gênero na nova "história do capitalismo" e sobre o que se perde com isso, ver: HARTIGAN-O'CONNOR, Ellen. "The Personal is Political Economy”; STANLEY, Amy Dru. "Histories of Capitalism and Sex Difference" no número sobre "Politics in and of Women's History in the Early Republic" de: Journal of the Early Republic, v. 36, n. 2, p. 335-350, verão 2016. 
convergência estejam ainda por se delinear claramente. ${ }^{21}$ Se não for esse o objetivo principal do novo interesse pelo "global", parece-me que se o preço a pagar por uma "história global" for retorno triunfante da estrutura ao centro da explicação histórica, ele talvez seja alto demais. E os seus ganhos, talvez ilusórios.

Como resposta provisória, proponho que a pergunta teleológica, com toda a sua validade, deva necessariamente ser confrontada com o desafio do seu contrário. E talvez o "vice-versa" também seja verdadeiro. É possível que as duas perguntas centrais da história social ganhem com esse confronto mútuo.

Bem, tendo dito isso, gostaria de passar ao outro conjunto de questões que, como disse antes, poderia ser acrescentado à nossa lista de riscos, e que diz respeito à própria dinâmica da produção e circulação do conhecimento histórico. Uma das características potencialmente positivas da internacionalização dos estudos históricos está certamente na construção de redes globais de pesquisadores interessados em dar conteúdo empírico à história global. Ora, aqui a dinâmica institucional tem uma importância evidente: a promoção da circulação de pesquisadores, o desenvolvimento de pesquisas coletivas etcetera. É importante notar nesse âmbito o protagonismo das instituições europeias e norte-atlânticas na promoção dessas redes e dessas pesquisas. Brevemente, acho que há aqui duas coisas a considerar. A primeira diz respeito ao desequilíbrio e assimetria na construção dessas redes de pesquisa transnacionais. Penso diretamente no modelo capitaneado pelo Instituto Internacional de História Social de Amsterdã, que é ao mesmo tempo o mais conhecido e o mais bem-sucedido fomentador tanto das redes quanto das grandes pesquisas coletivas, bem como pioneiro - com as intervenções de Marcel van der Linden, Jan Lucassen e mais recentemente Leo Lucassen - no desenvolvimento de uma global labor history. ${ }^{22}$ Esse modelo se constituiu explicitamente em desafio a uma história do trabalho que pensava a Europa e o Ocidente antes de tudo, e apenas se interessava pela periferia como uma curiosidade, ou como um desdobramento da história do colonialismo europeu: a célebre tirada do "the West and the rest". Desde o início, a "global labor history" tentava exatamente desafiar isso, respondendo ao seu modo àquela necessidade de, nas palavras de Dipesh Chakhrabarty, "provincializar a Europa". ${ }^{23}$ Impossível não reconhecer o papel positivo que o Instituto desempenhou e ainda desempenha no fomento dessas redes de pesquisa e colaboração.

Mas o fato é que, a despeito das suas ótimas intenções (e a importância dos

21 O fato de esta pergunta não ser em absoluto nova no campo da história e das ciências sociais reforça a ideia de que, por um lado, não se trata de uma questão simples, e que certamente é afetada por conjunturas que superam a dinâmica estritamente acadêmica. Por outro lado, talvez a convergência que aponto aqui implique retornar às discussões anteriores sobre o tema que foram deslocadas do centro das atenções nas últimas décadas, mas que mantém uma força heurística inestimável. Exemplos disso são, por exemplo, as obras de Henri Lefebvre (por exemplo, LEFEBVRE, Henri. Critique of Everyday Life. The one-volume edition. Londres: Verso, 2014, mas cuja primeira edição francesa é de 1947) e Jean-Paul Sartre. Sobre este último, basta lembrar que a tensão entre o "singular" e o "universal" está no centro de um texto hoje esquecido, mas que foi muito inspirador quando inicialmente publicado em 1958: SARTRE, Jean-Paul. Questão de Método. São Paulo: Difel, 1972. Aqui estou inteiramente de acordo com Rafael Marquese, que mencionou recentemente esses livros como textos valiosos que deveriam ser revisitados no contexto atual (na palestra a que faço referência na nota 11).

22 Ver, por exemplo: LUCASSEN, Jan (ed.). Global Labour History. A State of the Art. Berna: Peter Lang, 2006. Sobre os projetos coletivos atualmente em desenvolvimento no Instituto, ver: https://socialhistory. org/es/node/1604 (Current Research Projects).

23 CHAKRABARTY, Dipesh. Provincializing Europe. Postcolonial Thought and Historical Difference. 2 ed., Princeton: Princeton University Press, 2009. Ver também, mais uma vez, as observações de Weinstein sobre essas questões no campo dos estudos sobre a história social do trabalho nos EUA no artigo citado anteriormente, "Globalizando a História do Trabalho". 
seus resultados), o paradoxo da empreitada, entretanto, é que as histórias globais e sobretudo aquelas produzidas no sul global - acabam sendo introduzidas em uma nova narrativa da história do trabalho que continua sob controle do "centro". Nesse contexto, parece sobrar à nossa periferia o papel de produzir o material empírico que será processado e transformado na nova narrativa da história global por pesquisadores e instituições localizados e financiados pelas antigas potências coloniais.

Bem, aqui convém dizer duas coisas: eu mesmo fui beneficiado mais de uma vez, tanto profissional quanto intelectualmente, pela aproximação a essas redes e consigo ver muito bem o potencial positivo que esses esforços têm para a produção de outras narrativas e outras pesquisas. Também acredito que o paradoxo que apontei não escapa aos colegas de Amsterdã, e talvez não possam fazer muita coisa sobre isso, na medida em que essas assimetrias de poder e recurso não são uma perversão do sistema, mas definem a própria condição da sua existência e constituem parte do enquadramento institucional que dá forma à própria possibilidade das pesquisas e trocas de que estou falando. Não podem ser, portanto, simplesmente abolidas por um ato de vontade. Mas essa é uma questão importante para nós, isto é, para que possamos pensar nossa própria inserção e papel nessas redes, e nossas próprias estratégias para lidar com nossa posição assimétrica nelas. Me parece que, se vamos aceitar o "desafio" da história global, é importante redobrar a atenção para o risco intrínseco de manter essa narrativa do global dentro de uma matriz de produção e circulação do conhecimento que confirma mais uma vez o papel de liderança e protagonismo desses centros, e nosso papel periférico de consumidores de modelos interpretativos e conceitos históricos produzidos e cunhados alhures.

Como esse talvez seja um resultado inevitável da assimetria considerável de recursos (que no caso brasileiro ameaça a voltar a se intensificar), fica a pergunta se, independente dos seus resultados potenciais, a história global não tem como escapar da sua antiga vocação de ser uma história que confirma a importância dos países norte-atlânticos e a sua tutela sobre a grande narrativa do "global"? Se for isso mesmo, talvez seja o caso mesmo de abandonar unilateralmente a empreitada e continuar no caminho alternativo de pensar o que poderia ser o "global" quando visto, pensado e proposto a partir do "outro lado". Não há dúvidas que há motivos políticos suficientes para resistir a isso. Mas a pergunta fica: como lidar com esse problema? Se é que achamos que é, realmente, um problema.

Gostaria de mudar oângulo da conversa agora e tentar refletir um pouco sobre o que essa inflexão em direção ao global pode ter de potencialmente importante e útil. Aqui eu peço a paciência do(a) leitor(a), já que é um pouco da minha própria experiência que alimenta a conversa. A primeira vez que apresentei e discuti a minha pesquisa sobre contratos de trabalho envolvendo libertos da escravidão fora do Brasil foi em um encontro sobre a história do trabalho em Delhi, na Índia, há mais de uma década. ${ }^{24}$ Me lembro que foi ali que também ouvi pela primeira vez falar na "história global do trabalho". Apresentando minha pesquisa para uma comunidade acadêmica que tinha conhecimentos muito limitados sobre a história do Brasil, e ainda menos sobre a história da escravidão e do trabalho no país, eu não esperava encontrar o que encontrei, isso é, um debate vívido, extremamente rico em uma perspectiva comparada que produziu um efeito extraordinário sobre o modo como eu mesmo passei a ver meu objeto de pesquisa dali em diante. ${ }^{25}$

24 Trata-se do encontro bianual da Association of Indian Labour Historians (AILH), que acontece no V. V. Giri National Labour Institute em Noida, Delhi (Índia) e que teve, em 2018, a sua décima segunda edição. 
Para muitos dos meus novos colegas na Índia (nem todos indianos, já que era um encontro que envolvia pessoas de vários lugares: pesquisadores europeus, norteamericanos e africanos que também pesquisavam a África e a Ásia) aquela era uma oportunidade essencial para dar algum conteúdo à ideia de uma "história global do trabalho". ${ }^{6} \mathrm{Ou}$ - e isso me parece essencial -, uma oportunidade única para, em um grupo que reunia pessoas de várias partes do globo, discutir quais perguntas poderíamos formular em comum, e como as respostas particulares, localizadas, encontradas em cada uma de nossas pesquisas individuais, poderia nos ajudar a formular novas perguntas.

O que havia de "global" na história do trabalho que se fazia ali?

Não há dúvida que aquele encontro, como outros que participei em outros lugares, e mesmo aqueles que o GT Mundos do Trabalho organizou no Brasil, ${ }^{27}$ tinham em comum o fato de que eram resultados do empreendimento coletivo, e francamente internacionalista, que deu origem ao debate sobre a "história global do trabalho". A mediação de instituições como o Instituto de História Social de Amsterdã e o SEPHIS (South-South Exchange Programm for the History of Development) ${ }^{28}$ foram fundamentais: fomentando e mesmo financiando parcialmente encontros como esses earticulando grupos de pesquisa em diferentes partes do globo, e no "sul global" de modo especial (colocando em contato pesquisadores da América Latina, África e Ásia). Independente dessas instituições, entretanto, os laços intelectuais e pessoais com essa rede de pesquisadores acabaram por se multiplicar nos últimos anos, com a presença de historiadores indianos, por exemplo, nos encontros internacionais organizados dentro da rede de pesquisadores brasileiros do GT-ANPUH “Mundos do Trabalho". ${ }^{29}$

Mas também havia aí outros aspectos desse processo de interconexão em escala mundial, ligados a dinâmicas institucionais mais amplas, mas também a contextos nacionais e locais: facilidades de comunicação e acesso à informação via internet, um momento (no caso do Brasil) de incremento dos recursos para financiamento de pesquisa e viagens de pesquisadores etc.

Para mim, entretanto, devo dizer que essa experiência - da qual ainda participo sempre que posso - marcou profundamente a minha própria opinião sobre a potencialidade de uma "história global". Não à possibilidade de construção de grandes modelos explicativos, nem grandes projetos de pesquisa em escala transnacional, e menos ainda pela possibilidade de construção de uma

versão muito modificada da minha apresentação em Delhi em 2008: "Freedom, Precariousness and the Law: Freed Persons Contracting out their Labour in Nineteenth-Century Brazil”. International Review of Social History, v. 54, n. 3, p. 391-416, 2009.

26 E aqui, é preciso notar que a mediação institucional é mais uma vez muito importante: o encontro bianual da AILH, bem como a criação da própria associação, foi apoiado institucionalmente pelo Instituto de História Social de Amsterdã e teve o suporte e presença pessoal de Marcel van der Linden (que foi diretor de pesquisa do Instituto até 2014) e Jan Lucassen em praticamente todas as suas edições.

27 Me refiro aos encontros bianuais do GT que, desde aquele realizado em 2010 em Florianópolis (com o tema "Histórias do Trabalho desde o Sul Global"), são chamados de "Seminário Internacional" e que teve em Porto Alegre, em setembro de 2018, sua quinta edição. Ver o sítio desse coletivo de historiadores na internet: https://gtmundosdotrabalho.org.

28 O SEPHIS (South-South Exchange Programm for the History of Development) foi um programa originalmente estabelecido em 1994 pelo Ministério de Cooperação para o Desenvolvimento da Holanda, e sediado no Instituto de História Social de Amsterdã. Seus objetivos eram desenvolver a produção de conhecimento e a interação intelectual entre os países do chamado "Sul Global”, financiando projetos de pesquisa comparativos/ conectados e a mobilidade de pesquisadores. No seu formato original, o SEPHIS manteve-se ativo até 2013, quando passou a sediar-se no Brasil. Ver o sítio do SEPHIS na internet: http://sephis.org/en/about-us/sephis.

29 Destacando, por exemplo, a presença dos historiadores indianos sediados em Delhi, Chitra Joshi, Rana Behal e Prabhu Mohapatra nesses e outros encontros. 
nova grande narrativa sobre a modernidade globalizada, mas pela oportunidade ímpar de "desprovincializar" 30 a minha própria pesquisa. Isto é, por um lado, pensar meus temas de investigação fora e além do enquadramento nacional ou local como eu havia proposto em primeiro lugar. Por outro, a possibilidade que aquela experiência me deu de pensar a partir de categorias, de comparações e de perguntas que não eram "nativos" ao meu trabalho. Por outro lado, "desprovincializar" também porque pude ver a minha pesquisa ser apropriada por outros para fazerem suas próprias perguntas, em contextos históricos radicalmente diferentes daquele em que eu formulei o meu questionário em primeiro lugar.

Pensando retrospectivamente esse meu primeiro encontro com a história global, e todo o debate que acompanhei depois disso, eu me vejo cada vez mais de acordo com as objeções que o historiador italiano Giovannni Levi costuma fazer sobre uma a história global em sua visão restritiva. Segundo Levi, uma "história global" de fato, não existe. Ou melhor, se ela existe, não é como uma história que procura respostas gerais para perguntas gerais, porque respostas gerais (poderíamos dizer globais) não existem. ${ }^{31}$ Ao contrário, a única forma que algo como uma "história global" pode adquirir é a da micro-história, isto é, de uma ciência das perguntas gerais/globais e das respostas locais.

Mas como formular perguntas globais? E como fazer com que nossas pesquisas possam ressoar de modo a reformular as perguntas gerais/globais que as pessoas fazem em outros lugares? Acho que a resposta a esta pergunta não pode ser dada pela teoria. Em outras palavras, só pode acontecer na própria pesquisa, e é central para pensarmos nossa própria relação com o debate sobre a "história global": não se trata de abraçar modelos, mas abrir-se à possibilidade de formular nossas perguntas em confronto com um mundo mais amplo de pesquisa e comparação. Os desafios operacionais são grandes e dependem de dinâmicas institucionais e acadêmicas que muitas vezes não estão sob nosso controle. Mais uma vez, as dinâmicas institucionais também importam, e é preciso reconhecer a importância dos eventos organizados pelo GT "Mundos do Trabalho" como exemplos do tipo de ação coletiva que pode ajudar a fomentar esses processos de autorreflexão, desenvolvimento de espaços de trocas historiográficas, bem como de experimentação e provocação mútua. Outras iniciativas, inspiradas por essa agenda, podem e devem ainda ser pensadas e tentadas.

Gostaria de concluir em uma chave otimista, chamando para me ajudar o humor e o espírito internacionalista de Benedict Anderson. Ele que estudou as sociedades do Sudeste Asiático por toda a sua vida, lembrava sempre de um provérbio comum nas culturas da Indonésia e da Tailândia, que contava a história de um sapo que havia nascido e vivido toda a sua vida sob uma casca virada de coco. "Sentado calmamente sob a sua casca, depois de algum tempo, o sapo começou a acreditar que aquela casca de coco era todo o universo". "O julgamento moral dessa história”, dizia Anderson, “é que esse sapo, acomodado, de mentalidade estreita e provinciana, estava muito satisfeito consigo mesmo sem ter nenhuma razão para isso". Nas últimas palavras da sua bela autobiografia, publicada postumamente, Anderson escreveu, no espírito de um Marx bem humorado, aquele que poderia ser o grito de guerra não oficial de uma "história global” realmente interessante.

30 Deixo a palavra em aspas para marcar a referência ao conceito de "provincialização" de Chakrabarty, do qual obviamente deriva.

31 LEVI, Giovanni. “Micro-história e História Global”. História Crítica, n. 69, p. 21-35, 2018. Todo esse volume da revista colombiana, organizado por Levi, trata da relação entre história global e micro-história. 
Eu vou concluir minha intervenção com as suas palavras:

"Os sapos, em sua luta pela emancipação, nada têm a perder, a não ser as suas escuras cascas de coco. Sapos do mundo, uni-vos!". 32

Recebido em 25/11/2018

Aprovado em 12/12/2018 